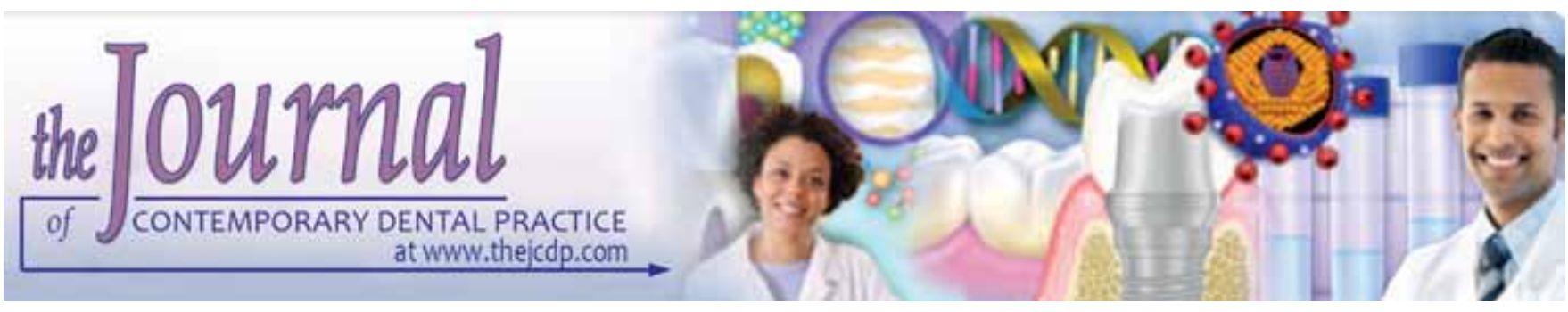

\title{
Fluoride releasing and Uptake Capacities of Esthetic Restorations
}

\author{
M Gururaj, Rajesh Shetty, Moksha Nayak, Shwetha Shetty, CN Vijay Kumar
}

\section{ABSTRACT}

Background and objectives: The purpose of this study was to evaluate and compare in vitro the fluoride release and uptake from 5 different esthetic restorative materials.

Materials and methods: Materials tested were conventional GIC - Fuji 7, GC (group1), resin modified GIC — Vitremer, 3M ESPE (group 2), polyacid modified composite - Dyract, Dentsply (group 3), fluoride releasing composite - Tetric ceram, Ivoclar Vivadent (group 4), Giomer-Beautifil, Shofu (group 5). Fluoride release was estimated at 6th, 24th, 48th hour and weekly interval for 5 weeks. For fluoride recharge, each specimen was exposed to $2 \mathrm{ml}$ of $1.23 \%$ APF gel for 4 minutes and fluoride release measured at 1 st, 2 nd, 3rd day and 7 th day. The fluoride release and recharge was measured using fluoride ion specific electrode.

Results: ANOVA and Tukey HSD test were used for statistical analysis. During tested period all materials showed statistically different capability to release and uptake fluoride. Groups 1 and 2 results were comparable in fluoride release. Similarly groups 3 and 5 . Groups 1 and 2 vs 3, 4, 5 were statistically very highly significant. Only conventional GIC showed initial 'burst effect'.

Interpretation and conclusion: Materials tested showed potential for fluoride release and recharge. Different esthetic materials had variable fluoride release hence selection of materials should be guided by specific clinical situations.

Keywords: Fluoride release, Esthetic restorations, Fluoride recharge.

How to cite this article: Gururaj M, Shetty R, Nayak M, Shetty $\mathrm{S}$, Kumar CNV. Fluoride releasing and Uptake Capacities of Esthetic Restorations. J Contemp Dent Pract 2013;14(5): 887-891.

Source of support: Nil

Conflict of interest: None declared

\section{INTRODUCTION}

Caries is a dynamic process in which mineral is removed during times of high acid production by bacterial plaque (demineralization) and replaced during periods of neutral $\mathrm{pH}$ (remineralization). ${ }^{1}$ Fluoride has been well-documented as a major contributing factor for the decline in the incidence and severity of dental caries and plays a central role in prevention of dental caries. ${ }^{2}$

Today, there are several fluoride-containing dental restoratives available in the market to reduce recurrent caries including glass-ionomers, resin modified glass-ionomer cements, polyacid-modified composites (compomers), composites and giomers. ${ }^{3-7}$ Due to their different matrices and setting mechanisms the products vary in their ability to release fluoride. However, cariostatic action associated with fluoride releasing materials is usually attributed to substantial release of fluoride. ${ }^{9}$

The use of restorative materials with the highest longterm fluoride release is preferable, especially in patients with moderate-to-high caries activity. ${ }^{10}$ The exact minimal fluoride concentration for caries inhibition has not been determined. ${ }^{11}$ Hence, fluoride lost can be replaced by 'recharging'. Recharging can be achieved by means of professionally applied topical fluoride gels, varnishes, fluoridated mouthrinses and dentifrices.

The purpose of this in vitro study was to compare the fluoride release and uptake capacity in artificial saliva from representative formulations of conventional GIC, resin modified glass ionomer, compomer, fluoride releasing composite and giomer restorative materials used as esthetic restorative materials.

\section{MATERIALS AND METHODS}

This study was conducted at the Department of Conservative and Endodontics, KVG Dental College, Sullia, and Environmental Engineering Lab, Department of Civil Engineering, National Institute of Technology, Surathkal, Karnataka.

The study was done using 5 types of fluoride releasing restorative materials, which were commercially available in India at the time of study. The materials selected were divided in to five groups as follows: 


\begin{tabular}{|c|c|c|}
\hline Group & Material used & Composition \\
\hline 1 & $\begin{array}{l}\text { Conventional glass } \\
\text { ionomer cement } \\
\text { (Fuji 7, GC Corp) }\end{array}$ & $\begin{array}{l}\text { Powder: Aluminofluorosilicate } \\
\text { glass, pigment. } \\
\text { Liquid: poly acrylic acid, distilled } \\
\text { water, polybase carboxylic acid }\end{array}$ \\
\hline 2 & $\begin{array}{l}\text { Resin modified } \\
\text { glass ionomer } \\
\text { cement (Vitremer, } \\
\text { 3M ESPE) }\end{array}$ & $\begin{array}{l}\text { Powder: fluoroaluminosilicate } \\
\text { glass } \\
\text { Liquid: modified polyalkenoic acid } \\
\text { and HEMA }\end{array}$ \\
\hline 3 & $\begin{array}{l}\text { Polyacid modified } \\
\text { composite } \\
\text { (Dyract, Dentsply) }\end{array}$ & $\begin{array}{l}\text { Filler }[75 \%(w t)] \text { : strontium-Al-Na- } \\
\text { fluoro-P-silicate-glass, strontium } \\
\text { fluoride } \\
\text { Matrix [25\% (wt)]: UDMA, TCB } \\
\text { resin, methacrylate - monomer }\end{array}$ \\
\hline 4 & $\begin{array}{l}\text { Fluoride releasing } \\
\text { composite } \\
\text { (Tetric Ceram, } \\
\text { Ivoclar vivadent) }\end{array}$ & $\begin{array}{l}\text { Matrix: Bis-GMA, UDMA, } \\
\text { TEGDMA } \\
\text { Filler: } \mathrm{Ba}-\mathrm{Al}-\mathrm{F}-\mathrm{Silicate} \text { glass, } \mathrm{Ba} \\
\text { glass, } \mathrm{SiO}_{2}, \mathrm{YbF}_{3}\end{array}$ \\
\hline 5 & $\begin{array}{l}\text { Giomer (S-PRG) } \\
\text { (Beautifil, Shofu) }\end{array}$ & $\begin{array}{l}\text { S-PRG, Fluoroboroalumino- } \\
\text { silicate glass, Bis-GMA, } \\
\text { TEGDMA, catalyst }\end{array}$ \\
\hline
\end{tabular}

A total of 50 specimens, 10 disk specimens for each group were prepared. The materials were manipulated as mentioned earlier. Specimens were prepared by filling the custom-made Teflon mold (diameter of $5 \mathrm{~mm}$, depth of $2 \mathrm{~mm}$ ) and Mylar strip was placed on the surface of the specimen, pressure was applied to extrude excess material. The specimens of group 1 were kept in the mold under matrix protection. Specimens of groups 2, 3, 4 and 5 were polymerized by light curing from the top surface with Quartz tungsten halogen light cure unit (Dentsply) with a light range of 400 to $500 \mathrm{~nm}$ according to the manufacturer's recommendations. Intensity of light source was checked with radiometer. After setting, specimens were removed from the mold.

Immediately after setting each specimen was immersed in individual polyethylene tube with $5 \mathrm{ml}$ of artificial saliva (wet mouth, ICPA). The fluoride estimation was done at $6 \mathrm{~h}, 24 \mathrm{~h}, 48 \mathrm{~h}$ and weekly intervals for 5 weeks. After aforementioned time interval the specimens were washed with deionized water spray, dried with absorbent paper and transferred to fresh polyethylene tube containing $5 \mathrm{ml}$ of artificial saliva (wet mouth, ICPA).

At the end of this period, the each specimen was recharged with $2 \mathrm{ml}$ of Fluorovil (1.23\% APF gel, Vishal Pharma) for 4 minutes. After the time elapsed, excess gel was vigorously washed off for 30 seconds with deionized water, dried with absorbent paper and transferred to new polyethylene tubes containing $5 \mathrm{ml}$ of artificial saliva (wet mouth, ICPA). The fluoride estimation was done at first, second, third and seventh day.

\section{DETERMINATION OF FLUORIDE ION RELEASE}

\section{Principle}

The fluoride electrode is an ion-selective sensor. The key element in the fluoride electrode is the laser-type doped lanthanum fluoride crystal across which a potential is established by fluoride solutions of different concentrations. The crystal contacts the sample solution at one face and an internal reference solution at the other. A potential is established by the presence of fluoride ions across the crystal which is measured by a device called ion meter or by any modem having an expanded millivolt scale. Fluoride activity depends on the total ionic strength of the sample.

\section{Procedure}

\section{Instrument Calibration}

Calibration of the fluoride electrode was determined before each measurement session using standard fluoride solutions (Orion Research Inc) containing 0.1, 0.5, 1, 5 and 10 ppm fluoride.

\section{Treatment of Sample}

$5 \mathrm{ml}$ of artificial saliva (wet mouth, ICPA), used for immersion of individual disk specimens was dispensed in to a beaker. An equal amount of TISAB (total ionic strength acetate buffer) solution was added to stabilize the $\mathrm{pH}$. The total volume was sufficient to immerse the electrode and permit the operation of stirring bar.

\section{Measurement with Electrode}

Electrodes were immersed in the sample solution and solution was stirred with magnetic stirrer. Stirring before immersion of electrodes should be avoided because entrapped air around the crystal can produce erroneous reading. Electrodes were left in the solution (average of 3 minutes) until reading is constant before taking final reading. Electrodes were withdrawn, rinsed with distilled water and blotted dry between every readings.

For all groups' fluoride ion concentration were calculated in parts/million/microgram of fluoride $/ \mathrm{sq} \mathrm{cm}$.

\section{RESULTS}

Table 1 shows the mean fluoride release (ppm) from groups $1,2,3,4$ and 5 during test intervals up to 5 weeks and recharge thereafter for 1 week.

Graph 1 line graph shows the mean values of fluoride released from 5 groups during test intervals up to 5 weeks and recharge thereafter for 1 week following:

- Mean fluoride release in group 1 reached a peak of $1.96 \mathrm{ppm}$ at 48 hours, there by slowly declined with fluoride release of $0.99 \mathrm{ppm}$ at 5 th week. Recharging capability was highest in day 1 of $1.60 \mathrm{ppm}$, thereafter gradually decreased reaching a value of 1.03 after 1 week. 
- Mean fluoride release in group 2 reached a peak of $2.54 \mathrm{ppm}$ at 1 week, there by slowly declined with fluoride release at $1.47 \mathrm{ppm}$ at 5 th week. Recharging capability was highest in day 1 of $2.04 \mathrm{ppm}$, thereafter decreased reaching a value of $1.55 \mathrm{ppm}$ at 1 week.

- Mean fluoride release in group 3 was highest at 1 week of $0.92 \mathrm{ppm}$, there by slowly declined with fluoride release at $0.61 \mathrm{ppm}$ at 5 th week. Recharging capability was highest in day 1 of $0.87 \mathrm{ppm}$, and decreased to 0.64 ppm at 3 day and was stable thereafter reaching $0.67 \mathrm{ppm}$ after 1 week.

- Mean fluoride release in group 4 was highest at 2 week of $0.52 \mathrm{ppm}$, there by slowly declined with fluoride release at $0.33 \mathrm{ppm}$ at 5 th week. Recharging capability was minimal showing value of $0.40 \mathrm{ppm}$ in day 1 and decreased to $0.30 \mathrm{ppm}$ at 3 day and was stable thereafter at $0.31 \mathrm{ppm}$ after 1 week.

- Fluoride release in group 5 was highest at 2 week of $1.01 \mathrm{ppm}$, there by slowly declined reaching $0.65 \mathrm{ppm}$ at 5 th week. Recharging capability was highest at day 1 of $0.93 \mathrm{ppm}$ and decreasing to value of 0.83 after 1 week.

Graph 2 shows the comparison of mean fluoride release after recharge from day 1 to 1 week.
- Results from graph show that group 1 had highest recharge capacity with mean value of 0.57 followed group 2 which had mean value of 0.49 .

- Group 4 showed least recharging capacity with mean value of 0.09 .

- Groups 4 and 5 showed an intermediate recharging capacity.

\section{DISCUSSION}

The increased use of caries preventive dental materials is required when accomplishing restorative procedures for patients at high risk of developing dental caries. The present study aimed at comparing the fluoride release and uptake capacities of 5 different esthetic restorative materials namely conventional glass ionomer cement (Fuji 7), Resin modified glass ionomer cement (Vitremer), Poly acid modified composite (Dyract), Fluoride releasing composite (Tetric Ceram) and Giomer (Beautifil).

Artificial saliva was adopted as the test medium in order to simulate the in vivo condition. The present study utilized fluoride ion specific electrode (ORION, 94098N) and Orion microprocessor ion analyzer (ORION, 960) since it is a simple and convenient method.

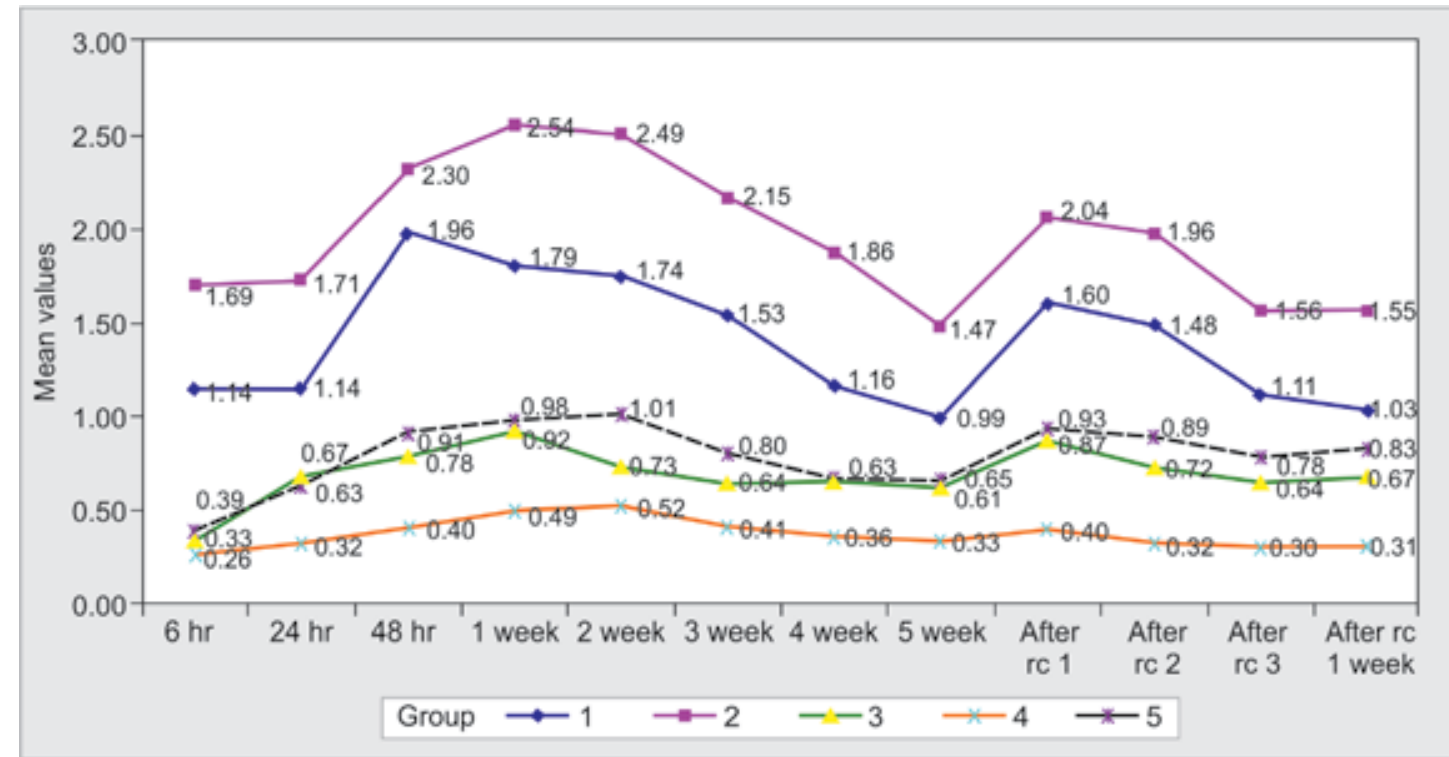

Graph 1: The mean values of flouride released form 5 groups during test intervals up to 5 weeks and recharge threreafter for 1 week

\begin{tabular}{|c|c|c|c|c|c|c|c|c|c|c|c|c|}
\hline Group & $\begin{array}{l}\text { 6th } \\
\text { hour }\end{array}$ & $\begin{array}{c}24 \\
\text { hours }\end{array}$ & $\begin{array}{c}48 \\
\text { hours }\end{array}$ & $\begin{array}{c}1 \\
\text { week }\end{array}$ & $\begin{array}{c}2 \\
\text { week }\end{array}$ & $\begin{array}{c}3 \\
\text { week }\end{array}$ & $\begin{array}{c}4 \\
\text { week }\end{array}$ & $\begin{array}{c}5 \\
\text { week }\end{array}$ & $\begin{array}{c}\text { After } \\
\text { recharge } \\
1 \text { day }\end{array}$ & $\begin{array}{c}2 \\
\text { day }\end{array}$ & $\begin{array}{c}3 \\
\text { day }\end{array}$ & $\begin{array}{c}1 \\
\text { week }\end{array}$ \\
\hline 1. Conventional GIC & 1.14 & 1.14 & 1.96 & 1.79 & 1.74 & 1.53 & 1.16 & 0.99 & 1.60 & 1.48 & 1.11 & 1.03 \\
\hline 2. Resin modified GIC & 1.69 & 1.71 & 2.30 & 2.54 & 2.49 & 2.15 & 1.86 & 1.47 & 2.04 & 1.96 & 1.56 & 1.55 \\
\hline $\begin{array}{l}\text { 3. Polyacid modified } \\
\text { composite }\end{array}$ & 0.33 & 0.67 & 0.78 & 0.92 & 0.73 & 0.64 & 0.65 & 0.61 & 0.87 & 0.72 & 0.64 & 0.67 \\
\hline $\begin{array}{l}\text { 4. Fluoride releasing } \\
\text { composite }\end{array}$ & 0.26 & 0.32 & 0.40 & 0.49 & 0.52 & 0.41 & 0.36 & 0.33 & 0.40 & 0.32 & 0.30 & 0.31 \\
\hline 5. Giomer & 0.39 & 0.63 & 0.91 & 0.98 & 1.01 & 0.80 & 0.67 & 0.65 & 0.93 & 0.89 & 0.78 & 0.83 \\
\hline
\end{tabular}


Group 1 (Conventional Glass Ionomer Cement, Fuji 7) to have increased fluoride release for the first 24 to 48 hours reaching a peak at 48 hours thereafter decreased slowly to reach steady level at 5 th week. This study confirms previous observations that glass ionomer cements have initial 'high burst' up to 24 to 48 hours. ${ }^{2}$

Newly introduced Fuji 7 used in this study as a representative of conventional glass ionomer cement sets by an acid-base reaction between components and fluoride release is a consequence of this reaction. It has a property of 'command set,' i.e. setting reaction time can be reduced by $30 \%$ by light curing. Unique feature of this material is the absence of any resin component in the material to hasten the setting reaction.

Group 2 (Resin Modified Glass Ionomer, Vitremer) released the highest. Independently of time, the most fluoride releasing materials are the conventional glass ionomer cement and the resin modified glass ionomer cements. Groups 1 and 2 exhibited the highest fluoride recharging capacity because they have higher porosity. Water content in GICs and RMGICs is more than compomer and composite. Ca-Al-F-silicate glass fillers in glass ionomers and resinmodified glass ionomers are more soluble and thus release more fluoride. ${ }^{8}$ RMGICs may release more fluoride than GICs because the acid-base reaction is physically inhibited by the presence of a polymer network, making the materials more permeable for longer time intervals. (Rothwell et al).

In this study, group 3 [Dyract, polyacid-modified resin composites (PMRC)] clearly released less fluoride than conventional and RMGICs. They do not release much fluoride and do not have auto setting acid-base reaction, which occurs without photo-activation (Sidhu and Watson, 1995).

Group 4 (Tetric Ceram, fluoride releasing composite) released the least amount of fluoride among the tested materials. This can be attributed to poor solubility of the

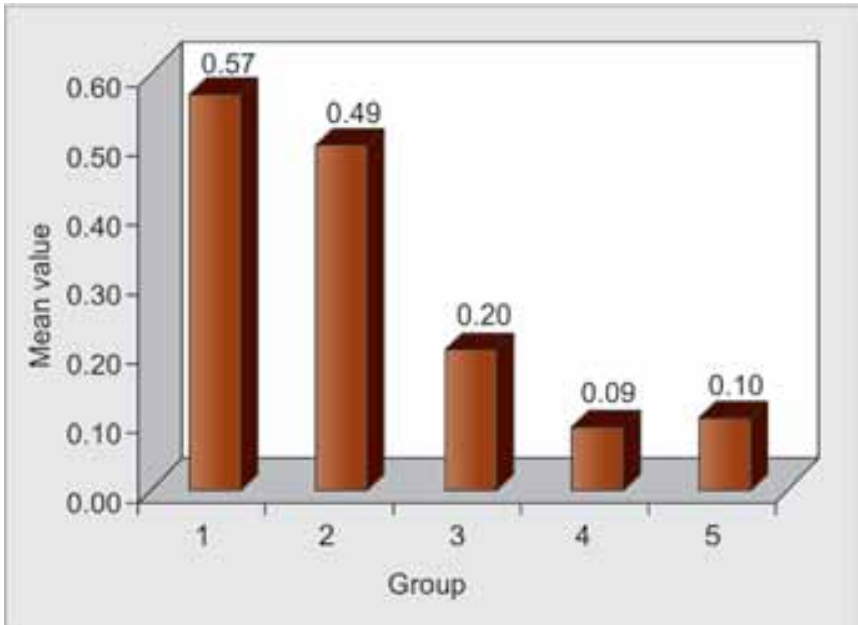

Graph 2: The comparison of mean flouride release after reacharge from day 1 to 1 week. fluoride containing salts (Ytterbium fluoride) and to a more tightly bound and/or less hydrophilic matrix of the resin composite. Showed least recharge capacity.

Group 5 (giomer, Beautifil) showed initial fluoride release more than that of groups 3 and 4, but it was less than groups 1 and 2. Although, the giomer did not have an initial burst effect, its cumulative fluoride release was more than the compomer. Beautifil contains both fillers fluoroaluminosilicate glass and surface pre reacted glass ionomer (S-PRG) as fluoride source. Water sorption is therefore not critical in the acid-base reaction process.

Optimum concentration of fluoride release to inhibit caries, Margolis et al in 1986 have shown enamel demineralization is decreased in fluoride concentration as low as $0.024 \mathrm{ppm}$ and inhibited at concentration of $1 \mathrm{ppm}$. Certainly material that could release $1 \mathrm{ppm}$ of fluoride over life of restoration would be desirable. ${ }^{11-16}$ Based on the previous studies it is recommended that materials with long term fluoride release rate of at least 2 to $3 \mu \mathrm{g} / \mathrm{ml} /$ day may be used in high risk group of patients. This can be achieved only by use of supplemental fluoride via recharge. Topical $1.23 \%$ acidulated phosphate fluoride (APF) treatments are recommended for children and adolescents who are at risk for dental caries (Wefel, 1985).

In the present study, application of APF gel to the specimens caused increase in fluoride release from all materials although; the patterns of release were variable. The exact mechanism of fluoride recharge is unknown. Several factors are likely to be involved in the process. Of these the permeability of the material is likely to be the factor that accounts for the differences between the materials. In this study groups 1 and 2 exhibited the highest fluoride recharging capacity. Materials with less resin content, such as glass ionomers, resin modified glass ionomers, have higher porosity. Therefore, they exhibit higher fluoride recharge capabilities. On the other hand, recharging capacities of materials used in study were as follows:

Group $4<$ group $5<$ group $3<$ group $2<$ group 1

\section{CONCLUSION}

The need for use of restorative materials with the highest long-term fluoride release is preferable, especially in patients with moderate-to high caries activity.

Within the limitations of present study it can be concluded that:

- All the materials tested in the study had the ability to release and recharge fluoride.

- Resin modified GIC showed consistently highest fluoride release among the tested materials, fluoride release and uptake was comparable with conventional glass ionomer cement. Fluoride releasing composite showed least fluoride release and uptake capacity. 
- Conventional glass ionomer cement showed initial 'burst' effect of fluoride from 24 to 48 hours whereas other materials did not show this effect.

- Giomer was comparable in fluoride release to polyacid modified composite although recharging capability of polyacid modified composite was higher than giomer.

- Patterns of fluoride release before and after recharge with $2 \mathrm{ml}$ of $1.23 \%$ APF gel for 4 minutes were similar except between giomer and polyacid modified composite.

- $1 \mathrm{ppm}$ values of fluoride release in artificial saliva initially were attained only with conventional GIC, resin modified GIC and giomer and after recharge from conventional GIC, resin modified GIC. From a clinical point of view, all the restorative materials tested may act as intraoral devices for the controlled slow release of fluoride at sites at risk of recurrent caries; however, selection of material should be done according to specific clinical situations.

\section{REFERENCES}

1. Burgess John O. Fluoride releasing materials. Fundamentals of operative dentistry - a contemporary approach. 2nd ed. Quintessence Inc 2001;377-385.

2. Freedman R, Diefenderfer KE. Effects of daily fluoride exposures on fluoride released by glass ionomer-based restoratives. Operative Dentistry 2003;28(2):178-185.

3. Vivien Castioni N, Baehni PC, Gurny R. Current status in oral fluoride pharmacokinetics and implications for the prophylaxis against dental caries-review article. European Journal of Pharmaceutics and Biopharmaceutics 1998;45:101-111.

4. Gandolfia MG, Chersonib S, Acquavivab GL, Pianab G, Pratib $\mathrm{C}$, Mongiorgia R. Fluoride release and absorption at different pH from glass ionomer cements. Dental Materials 2006;22: 441-449.

5. Knight GM, McIntyre JM, Mulyani. Ion uptake into demineralized dentine from glass ionomer cements fallowing pretreatment with silver fluoride and potassium iodide. Australian Dental Journal 2006;51-3:237-241.

6. Dionysopoulos P, Kotsanos N, Koliniotou-Koubia E, Tolidis $\mathrm{K}$. Inhibition of demineralization in vitro around fluoride releasing materials. Journal of Oral Rehabilitation 2003;30: 1216-1222.

7. Vermeersch G, Leloup G, Vreven J. Fluoride release from glass-ionomer cements, compomers and resin composites. Journal of Oral Rehabilitation 2001;28:26-32.

8. Xu X, Burgess John O. Compressive strength, fluoride release and recharge of fluoride-releasing materials. Biomaterials 2003;24:2451-2461.
9. Sunico MC, Shinkai K, Katoh Y. Two-year clinical performance of occlusal and cervical giomer restorations. Operative Dentistry 2005;30-3:282-289.

10. Helvatjoglu-Antoniades M, Karantakis P, Papadogiannis Y, Kapetanios H. Fluoride release from restorative materials and a luting cement. J Prostheti Dent 2001;86:156-164.

11. Strother JM, Kohn DH, Clarkson BH. Fluoride release and re-uptake in direct tooth colored restorative materials. Dental Materials 1998 March;14:129-136.

12. De Moor Roeland JG, Verbeeck Ronald MH, De Maeyer Erna AP. Fluoride release profiles of restorative glass ionomer formulations. Dental Materials 1996 March;12:88-95.

13. Preston AJ, Higham SM, Agalamanyi EA, Mair LH. Fluoride recharge of aesthetic dental materials. J Oral Rehabilitation 1999;26:936-940.

14. Hsua HM, Huang GF, Chang HH, Wang YL, Guob MK. A continuous flow system for assessing fluoride release/uptake of fluoride-containing restorative materials. Dental Materials 2004;20:740-749.

15. Preston AJ, Mair LH, Agalamanyi EA, Higham SM. Fluoride release from aesthetic dental materials. J Oral Rehabilitation 1999;26:123-129.

16. Mickenautsch S, Mount G, Yengopal V. Therapeutic effect of glass-ionomers: an overview of evidence. Australian Dental Journal 2011;56:10-15.

\section{ABOUT THE AUTHORS}

\section{Gururaj (Corresponding Author)}

Reader, Department of Conservative Dentistry and Endodontics New Horizon Dental College and Research Institute, Sakri, Bilaspur Chhattisgarh, India, e-mail: drgururajm@gmail.com

\section{Rajesh Shetty}

Professor and Head, Department of Conservative Dentistry and Endodontics, Dr DY Patil Dental College and Hospital, Dr DY Patil Vidyapeet, Pimpri, Pune, Maharashtra, India

\section{Moksha Nayak}

Principal, Department of Conservative Dentistry and Endodontics KVG Dental College and Hospital, Sullia. Dakshin Kannada Karnataka, India

\section{Shwetha Shetty}

Reader, Department of Prosthodontics and Crown and Bridge, Dr DY Patil Dental College and Hospital, Dr DY Patil Vidyapeet, Pimpri Pune Maharashtra, India

\section{CN Vijay Kumar}

Reader, Department of Conservative Dentistry and Endodontics, KVG Dental College and Hospital, Sullia, Dakshin Kannada, Karnataka India 